\title{
Macrophages That Have Ingested Apoptotic Cells In Vitro Inhibit Proinflammatory Cytokine Production Through Autocrine/Paracrine Mechanisms Involving TGF- $\beta$, PGE2, and PAF
}

Valerie A. Fadok, Donna L. Bratton, Anatole Konowal, Peter W. Freed, Jay Y. Westcott, ${ }^{\star}$ and Peter M. Henson

Department of Pediatrics and $*$ Department of Medicine, National Jewish Medical and Research Center, Denver, Colorado 80206

\begin{abstract}
Apoptosis in vivo is followed almost inevitably by rapid uptake into adjacent phagocytic cells, a critical process in tissue remodeling, regulation of the immune response, or resolution of inflammation. Phagocytosis of apoptotic cells by macrophages has been suggested to be a quiet process that does not lead to production of inflammatory mediators. Here we show that phagocytosis of apoptotic neutrophils (in contrast to immunoglobulin G-opsonized apoptotic cells) actively inhibited the production of interleukin (IL)-1 $\beta$, IL-8, IL-10, granulocyte macrophage colony-stimulating factor, and tumor necrosis factor- $\alpha$, as well as leukotriene $\mathrm{C}_{4}$ and thromboxane B2, by human monocyte-derived macrophages. In contrast, production of transforming growth factor (TGF)- $\beta 1$, prostaglandin E2, and platelet-activating factor (PAF) was increased. The latter appeared to be involved in the inhibition of proinflammatory cytokine production because addition of exogenous TGF- $\beta 1$, prostaglandin E2, or PAF resulted in inhibition of lipopolysaccharide-stimulated cytokine production. Furthermore, anti-TGF- $\beta$ antibody, indomethacin, or PAF receptor antagonists restored cytokine production in lipopolysaccharide-stimulated macrophages that had phagocytosed apoptotic cells. These results suggest that binding and/or phagocytosis of apoptotic cells induces active antiinflammatory or suppressive properties in human macrophages. Therefore, it is likely that resolution of inflammation depends not only on the removal of apoptotic cells but on active suppression of inflammatory mediator production. Disorders in either could result in chronic inflammatory diseases. (J. Clin. Invest. 1998. 101:890-898.) Key words: apoptosis • inflammation • eicosanoids • mediators $\bullet$ phagocytosis
\end{abstract}

\section{Introduction}

Phagocytosis by macrophages or other cells is the final event in the lives of many cells undergoing apoptosis $(1,2)$. Apoptotic cells express cell surface changes which allow recognition and

Address correspondence to Valerie A. Fadok, D509, National Jewish Medical and Research Center, 1400 Jackson Street, Denver, CO 80206. Phone: 303-398-1281; FAX: 303-398-1381; E-mail: Valerie_Fadok.PEDIATRICS@mac.njc.org

Received for publication 7 July 1997 and accepted in revised form 5 December 1997.

J. Clin. Invest.

(C) The American Society for Clinical Investigation, Inc. 0021-9738/98/02/0890/09 \$2.00

Volume 101, Number 4, February 1998, 890-898

http://www.jci.org removal by macrophages. Removal occurs before lysis, which prevents the release of potentially toxic and immunogenic intracellular contents from the apoptotic cells into the surrounding tissue. Thus, in tissues such as the thymus in which apoptosis is ongoing, normal structure and function are maintained and inflammation is avoided. The removal of apoptotic cells also appears to be critical in the resolution of inflammation. Phagocytosis of apoptotic cells in inflammatory sites has been documented in vivo in experimental as well as clinical disease states, and disorders of apoptosis have been suggested to contribute to the persistence of chronic inflammatory conditions in the lung, kidney, and other organs (3-5).

The mechanisms by which apoptotic cells can be recognized and removed have received extensive study in the last few years. A number of receptors have been identified in vitro. These include an uncharacterized lectin inhibited by $N$-acetylglucosamine (6), the vitronectin receptor ( $\alpha \mathrm{v} \beta 3$ integrin) which is thought to cooperate with CD36 in binding to thrombospondin on the surface of the apoptotic cell $(7,8)$, a phosphatidylserine (PS) ${ }^{1}$-specific receptor (9-12), scavenger receptors (13-15), and the macrophage antigen identified by the mAb 61D3 (16), which may be identical to, or related to, CD14 (Devitt, A., C. Raykundalia, O.D. Moffatt, J.D. Capra, D.L. Simmons, and C.D. Gregory, manuscript submitted for publication). The $\mathrm{ABC} 1$ transporter has also been suggested to be involved in phagocytosis (17). The mechanisms by which any of these receptors facilitate apoptotic cell uptake are not known. The changes on the apoptotic cell which induce recognition by macrophages have also not been well characterized. Exposure of PS on the surface of apoptotic cells is associated with phagocytosis by macrophages of some phenotypes (10-12). Loss of membrane phospholipid asymmetry and early external expression of PS have been documented on many different cell types undergoing apoptosis and the mechanisms mediating this membrane change are an area of active study (10,18-23). Other changes reported to occur include expression of immature sugars on apoptotic thymocytes and hepatocytes $(24,25)$, the expression of ICAM-3 on apoptotic B cells which facilitates recognition by macrophages via a lymphocyte functionassociated antigen-1-independent pathway (26), specific loss of surface expression of some (but not all) GPI-linked protein antigens, such as CD16 on apoptotic neutrophils $(22,27)$, and exposure of novel uncharacterized antigens recognized by mAbs on apoptotic cells in the embryonic chicken limb bud (28).

The effects of phagocytosis of apoptotic cells on the macrophage itself have not been characterized completely. Meagher et al. initially studied the effects of apoptotic neutrophil up-

1. Abbreviations used in this paper: MPO, myeloperoxidase; PAF, platelet-activating factor; PS, phosphatidylserine; TxB2, thromboxane $\mathrm{B} 2$. 
take on the human monocyte-derived macrophage and found no induction of $\mathrm{N}$-acetylglucosaminidase or thromboxane B2 (TxB2) (29). If, however, the same apoptotic cells were opsonized with antibody and then fed to macrophages, a brisk induction of these substances was observed. After the phagocytosis of apoptotic eosinophils by human macrophages, there was no increase in TxB2 or GM-CSF (30). In contrast, secretion of TxB2 and GM-CSF increased after engulfment of opsonized apoptotic eosinophils or necrotic eosinophils. These investigators hypothesized that phagocytosis of apoptotic cells by the VnR/CD36 mechanism did not lead to a macrophage response, whereas uptake mediated by the FcR was stimulatory. Thus, the receptor involved in apoptotic cell uptake determined the response by the macrophage.

Several questions remain to be answered however. Is this truly a passive lack of response or could the macrophage be actively suppressing proinflammatory mediator production? Is the suppression peculiar to GM-CSF or are other proinflammatory cytokines involved? What about the effects on eicosanoids other than TxB2? Based on our previous work, we knew that macrophages which had ingested digestible particulate stimuli secreted TGF- $\beta(11,31,32)$. Since apoptotic cells are digestible particles (albeit large ones), it is reasonable to hypothesize that phagocytosis of apoptotic cells might induce the secretion of TGF- $\beta$, which would then act in an autocrine or paracrine fashion to inhibit the production of proinflammatory cytokines. TGF- $\beta$ has been shown previously to downregulate production of proinflammatory mediators in macrophages (for reviews see references 33 and 34). Therefore, we studied the effects of phagocytosis of apoptotic human neutrophils on the production of TGF- $\beta 1$, as well as GM-CSF, IL- $1 \beta$, IL-8, IL-10, and TNF- $\alpha$. Because the secretion of lipid inflammatory mediators could also be affected, the effects of apoptotic cell uptake on secretion of four eicosanoids, TxB2, LTC4, PGD2, and PGE2, were determined.

\section{Methods}

Reagents. DME and HBSS were purchased from GIBCO BRL (Gaithersburg, MD); X-Vivo 10 medium was purchased from BioWhittaker (Walkersville, MD). Mouse anti-human CD45 clone 2D1, IgG1 was purchased from Becton-Dickson (San Jose, CA), or clone H130, IgG1, к (PharMingen, San Diego, CA); rabbit anti-mouse IgG was purchased from Jackson ImmunoResearch Laboratories (West Grove, PA). LPS (Escherichia coli, serotype 0111:B14) was obtained from List Biological Laboratories (Campbell, CA); A23187 and zymosan were purchased from Sigma Chemical Co. (St. Louis, MO). Human TGF- $\beta 1$, anti-human TGF- $\beta$ antibody, human PDGF, antihuman PDGF, human IL-10, and anti-human IL-10 were purchased from R \& D Systems (Minneapolis, MN). Platelet-activating factor (PAF, alkyl chain a mix of $\mathrm{C} 18$ and $\mathrm{C} 16$ ) was purchased from Avanti Polar Lipids (Alabaster, AL). Eicosanoids and indomethacin were purchased from Cayman Chemical Co. (Ann Arbor, MI).

Cells. Human macrophages were prepared from peripheral blood mononuclear cells, as previously published (35). The cells were plated at $4 \times 10^{6} / \mathrm{ml}$ in 24-well plates for $60 \mathrm{~min}$ in DME, after which nonadherent cells were washed out with HBSS. The macrophages were cultured for $3 \mathrm{~d}$ in X-Vivo 10 medium containing $10 \%$ pooled human serum (five or more donors) prepared as described (36). The medium was changed at $3 \mathrm{~d}$. For all experiments, macrophages had been cultured for $6-8 \mathrm{~d}$ before use. This yielded 1-2 million macrophages per well at the time of the assay.

Human neutrophils were used as a source of apoptotic cells. Apoptosis was induced by $10 \mathrm{~min}$ of UV irradiation at $254 \mathrm{~nm}$ followed by culture in DME $+10 \%$ heat-inactivated FBS (Gemini Bioproducts, Calabasas, $\mathrm{CA}$ ) at $37^{\circ} \mathrm{C}, 5 \% \mathrm{CO}_{2}$ for $3-4 \mathrm{~h}$ by tumbling end-over-end in polypropylene tubes. At that time, apoptosis (assessed morphologically by light microscopy of stained cytocentrifuged cells) equaled or exceeded $60 \%$, whereas necrosis (assessed by trypan blue uptake) was $\leq 1 \%$. As a control particle, apoptotic human neutrophils were opsonized to induce uptake by $\mathrm{Fc}$ receptors for IgG. Apoptotic neutrophils were rotated end-over-end at $4^{\circ} \mathrm{C}$ with anti-CD 45 for $30 \mathrm{~min}$. After three washes, the secondary antibody rabbit anti-mouse IgG was added for an additional $30 \mathrm{~min}$. The cells were washed again and resuspended in X-Vivo 10 medium without serum for use in the phagocytosis assay.

Jurkat cells. Jurkat T cells were cultured in RPMI medium containing $20 \%$ FBS, glutamine $(2 \mathrm{mM})$, penicillin $(100 \mathrm{U} / \mathrm{ml})$, and streptomycin $(100 \mu \mathrm{g} / \mathrm{ml})$ at $37^{\circ} \mathrm{C}$ and $5 \% \mathrm{CO}_{2}$. When cell density reached $10^{6} / \mathrm{ml}$, the culture was UV-irradiated for $10 \mathrm{~min}$ as described above, then cultured for $2-2.5 \mathrm{~h}$. This routinely yielded populations containing $60-70 \%$ apoptotic cells and $5 \times 10^{6}$ were added to each well (24well plate) of macrophages. Uptake was confirmed by microscopy, as described below, except that Jurkat cells were not stained for myeloperoxidase (MPO).

Phagocytosis of apoptotic cells. Uptake was determined as described previously $(7-11,36)$. Apoptotic neutrophils were added to day 7-10 human monocyte-derived macrophages at $5 \times 10^{6}$ cell/well of a 24-well plate in X-Vivo 10 medium and incubated for $1 \mathrm{~h}$ at $37^{\circ} \mathrm{C} / 5 \%$ $\mathrm{CO}_{2}$. The monolayer was then washed vigorously with ice-cold PBS to remove bound but uningested neutrophils, fixed with $1 \%$ formalin overnight, and treated with one part dianisidine $(1.25 \mathrm{mg} / \mathrm{ml})$ to one part $0.05 \% \mathrm{H}_{2} \mathrm{O}_{2}$ to stain for MPO as a marker of the ingested neutrophils $(7,8,36)$. The macrophages themselves were routinely negative for peroxidase staining. Using $\times 40$ phase-contrast microscopy, uptake of apoptotic neutrophils was assessed, counting two replicate wells for each condition of 200 macrophages per well. Phagocytic index was calculated as the percentage of phagocytosing macrophages multiplied by the average number of neutrophils ingested per macrophage. Macrophages that showed discrete, round, MPO-positive inclusion(s) were scored as having ingested one (or more) apoptotic neutrophils. Neutrophils with margins extended $>50 \%$ beyond the edge of the macrophage cell membrane were scored as noningested. (This convention may have underestimated the number of phagocytosed neutrophils, because ultrastructural analyses have shown macrophages to engulf such neutrophils with a thin wall of cytoplasm [data not shown].) Phagocytosis as assessed by this method was confirmed in preliminary experiments by electron microscopy. For uptake of opsonized apoptotic cells, the same technique was used; however, varying numbers (1-5 million) were added per well to determine what number was needed to achieve equivalent phagocytosis to that for unopsonized apoptotic cells.

Collection of supernatants. Before use, macrophage monolayers were washed with HBSS, then X-Vivo 10 medium without human serum was added. Apoptotic cells or control particles were added and supernatants were collected $18 \mathrm{~h}$ later. This time point was chosen because preliminary experiments showed that cytokine secretion stimulated by LPS or zymosan was maximal. Phagocytosis was assessed by microscopy (see above) to ensure that uptake was equivalent for the two different particles. For some experiments, the apoptotic cells were washed out after $1 \mathrm{~h}$ and fresh X-Vivo 10 medium was added for another $18 \mathrm{~h}$. Supernatants were centrifuged at 2,000 rpm to remove particulate debris, then were stored in aliquots at $-70^{\circ} \mathrm{C}$. In some experiments, LPS at $1 \mathrm{ng} / \mathrm{ml}$ or zymosan at $50 \mu \mathrm{g} / \mathrm{ml}$ was added to stimulate cytokine production. Apoptotic cells or opsonized apoptotic cells were added at the same time of the stimulus.

Analysis of cytokines. Cytokine concentrations in the culture supernatants were determined by ELISA, using the Quantikine immunoassays manufactured by $\mathrm{R} \& \mathrm{D}$ Systems. The cytokines analyzed were GM-CSF, IL-1 $\beta$, IL-8, IL-10, TGF- $\beta 1$, and TNF- $\alpha$. Assays were performed according to the instructions provided with each kit. For TGF- $\beta 1$, the supernatants were acid-activated according to the manu- 
facturer's instructions before the assay. Color development was assessed using the microplate autoreader (EL309) by Bio-Tech Instruments (Winooski, VT). Data were analyzed using a $\log / \log$ curve fit option from Delta Soft 3 ELISA analysis software for the Macintosh (BioMetallics, Inc., Princeton, NJ).

Analysis of eicosanoids. PGD2, PGE2, LTC4, and TxB2 were quantified by enzyme immunoassays using acetylcholinesterase-conjugated tracers as described previously $(37,38)$. The rabbit polyclonal antibody for PGD2 was a gift from Dr. R.W. Kelly (Edinburgh, UK), while the rabbit polyclonal antibody for TxB2 was a gift from Dr. Frank Fitzpatrick (Pharmacia-Upjohn, Piscataway, NJ). The mouse $\mathrm{mAb}$ for the peptide leukotrienes was cross reactive with LTC4, LTD4, and LTE4 and was purchased from Perceptive Bioresearch Products (Cambridge, MA). LTC4 was used as the reference standard in assays and the peptidoleukotriene products referred to as LTC4. The mouse $\mathrm{mAb}$ used for the quantification of PGE2 was purchased from Cayman Chemical Co. Supernatant samples for LTC4, PGE2, and TxB2 were used without purification at dilutions of 1:5 to 1:10. Samples for PGD2 were derivatized with a methoxyamine reagent $\left(50 \mu \mathrm{l}\right.$ of sample and $50 \mu \mathrm{l}$ of reagent) by heating at $60^{\circ} \mathrm{C}$ for $1 \mathrm{~h}$ (39), and diluted to a final concentration of 1:5. Standard curves and samples were analyzed using the four-parameter curve fit option on Delta Soft 3 software. The sensitivity of the assays ranged from 4 to $16 \mathrm{pg} / \mathrm{ml}$.

Analysis of IL-8 and TNF- $\alpha$ mRNA levels by quantitative RT$P C R$. Total RNA was isolated from each macrophage population using the Micro-Scale Total RNA Separator kit produced by CLONTECH (Palo Alto, CA). Then, $2 \mu \mathrm{g}$ of product was checked for integrity by electrophoresis through a $1 \%$ formaldehyde agarose gel containing ethidium bromide. If intact, $1.2 \mu \mathrm{g}$ of the total RNA was used for first-strand cDNA synthesis, using CLONTECH's Advantage RT-for-PCR kit. PCR products were quantitated using competitive PCR with CLONTECH's PCR Mimics kits for IL-8 and TNF- $\alpha$; minor modifications included the use of $4 \mu \mathrm{l}$ of cDNA and MIMICS, rather than $2 \mu \mathrm{l}$, and electrophoresis of $12 \mu \mathrm{l}$ of sample in $2 \%$ ethidium bromide/agarose gel for detection and quantification. $\beta$-actin was used as a control and was not found to vary from experiment to experiment.

Statistical analysis. The means of the concentrations for each cytokine were analyzed using ANOVA for multiple comparisons; when ANOVA indicated significance, the Tukey-Kramer HSD test for all pairs was used to compare groups. For experiments in which exogenous inhibitors were used (see Figs. 5-7), Dunnett's method was used, with LPS-treated macrophages as the control. All data were analyzed using JMP (version 3) Statistical Software for the Macintosh (SAS Institute, Inc., Cary, NC).

\section{Results}

Phagocytosis of apoptotic cells does not stimulate the production of proinflammatory cytokines by human macrophages. Human monocyte-derived macrophages were given apoptotic human neutrophils or opsonized apoptotic neutrophils in a serum-free medium (X-Vivo 10). Preliminary experiments were performed to determine the ratio of opsonized cells to macrophages that should be added to achieve equivalent phagocytosis for both types of cells. In five experiments we found that $5 \times 10^{6}$ apoptotic cells added to each well of macrophages gave an average phagocytic index of 43.1 ( \pm 4.9 SEM), where the phagocytic index is defined as the product of the percentage of macrophages positive for phagocytosis (39.2) and the number of cells per macrophage (1.1). A similar phagocytic index for opsonized apoptotic cells $(39.1 \pm 5.7)$ was achieved using $10^{6}$ cells, with the percentage of positive macrophages equaling 35.5 and the number of neutrophils per macrophage equaling 1.1. Therefore, these cell numbers were used routinely for the

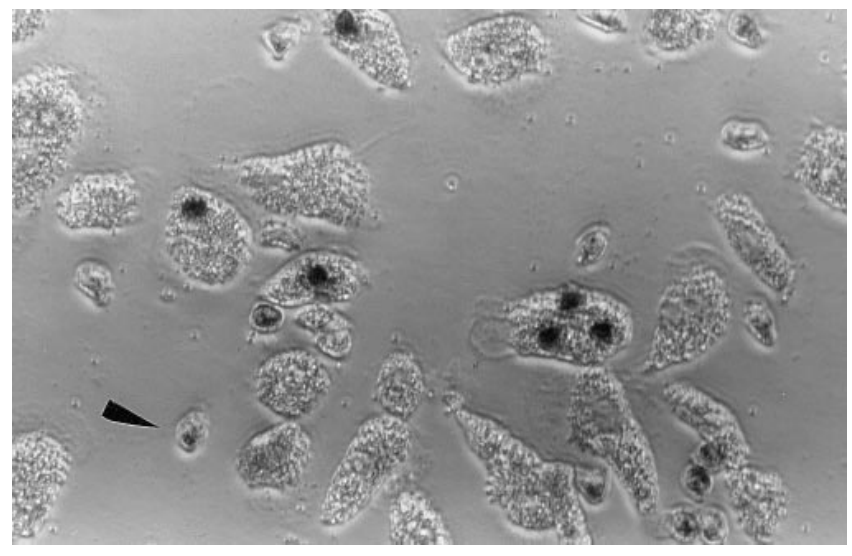

Figure 1. Photomicrograph of human monocyte-derived macrophages that have phagocytosed apoptotic neutrophils. The intracellular apoptotic neutrophils (stained for MPO) appear as condensed black bodies within the MPO-negative macrophages. The arrowhead indicates an unphagocytosed neutrophil.

cytokine experiments. Fig. 1 shows a photomicrograph of apoptotic neutrophils stained for MPO that have been ingested by human macrophages, using the same culture conditions as were used for assessment of cytokine production.

To determine what effects uptake of apoptotic cells would have, unstimulated macrophages were exposed to apoptotic cells for $18 \mathrm{~h}$ and supernatants were analyzed for cytokines. Preliminary data had indicated that IL-1 $\beta$, IL-8, IL-10, GMCSF, and TNF- $\alpha$ levels stimulated by opsonized zymosan or opsonized apoptotic cells were maximal around this time (data not shown). After $18 \mathrm{~h}$, macrophages which had phagocytosed apoptotic cells failed to increase production of GM-CSF, IL$1 \beta$, IL- 8 , IL-10, or TNF- $\alpha$, but stimulated release of TGF- $\beta 1$ to levels approximately three times that of control (Fig. 2). A slight increase $(40 \%)$ in TGF- $\beta 1$ levels induced by apoptotic cells was apparent as early as $1 \mathrm{~h}$ after addition of apoptotic cells (data not shown). In contrast, opsonized apoptotic cells stimulated increased production of all the cytokines except for TGF- $\beta 1$. As an additional control, we incubated apoptotic neutrophils alone for $18 \mathrm{~h}$ and measured cytokine levels in the harvested supernatant. Levels were undetectable for all of the cytokines (data not shown).

One of the potential problems with allowing the apoptotic neutrophils to remain in contact with the macrophages for $18 \mathrm{~h}$ was the possibility that they would undergo secondary necrosis and influence the results. This possibility was examined in two ways. First, apoptotic neutrophils that had become necrotic either spontaneously after time in culture or by heating to $56^{\circ} \mathrm{C}$ for 5-10 min were fed to macrophages. These experiments were repeated six times and the results were inconsistent. In three out of six experiments, the necrotic cells stimulated cytokine production, as was seen for necrotic eosinophils (31); however, in three experiments, there was no stimulation of cytokine secretion. This disparity may be due to variations in the necrotic cell preparation, since the neutrophils tended to clump together when they became necrotic. Therefore, we took a second approach. Macrophages were allowed to phagocytose apoptotic or freshly isolated neutrophils for $1 \mathrm{~h}$, at which time residual cells were removed by washing, and fresh medium (X-Vivo 10) was added. Supernatants were then col- 

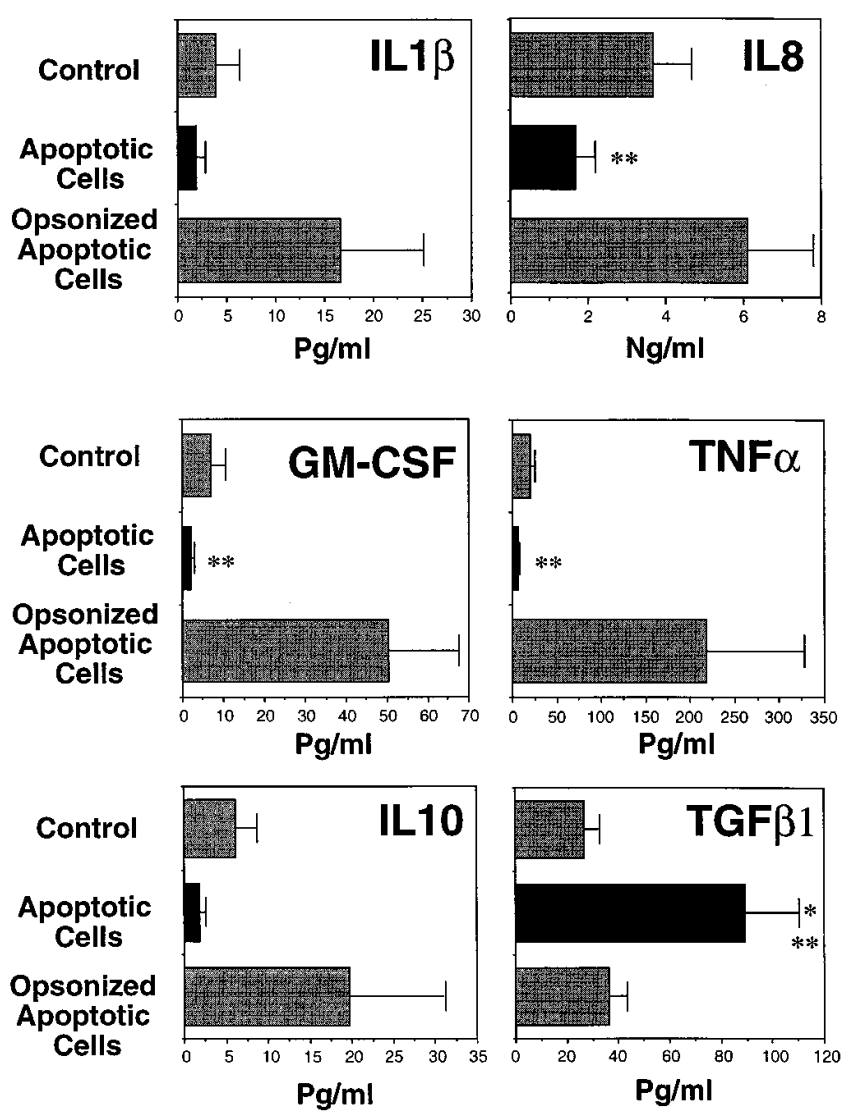

Figure 2. The effect of phagocytosis of apoptotic cells compared with opsonized apoptotic cells on macrophage cytokine production. Apoptotic human neutrophils or opsonized apoptotic neutrophils were added to human monocyte-derived macrophages and supernatants were collected $18 \mathrm{~h}$ later. Cytokine concentrations were determined by ELISA. As a control, macrophages were incubated for $18 \mathrm{~h}$ with no stimulus. Data are displayed as the mean cytokine production \pm SEM for 14 experiments; *significantly different from control and $* *$ significantly different from opsonized apoptotic cells $(P<0.05)$.

lected $18 \mathrm{~h}$ later. Although the total cytokine concentrations were lower, TGF- $\beta 1$ was stimulated by apoptotic neutrophils while the other cytokines were inhibited (data not shown). In contrast, freshly isolated neutrophils either showed no inhibition or stimulated proinflammatory cytokine production.

Inhibition of cytokine production after uptake of apoptotic cells. Phagocytosis of apoptotic cells appeared to decrease the production of all cytokines by macrophages except TGF- $\beta 1$ (Fig. 2); however, the decreases were not statistically significant since the levels of cytokine produced by unstimulated macrophages were low. Therefore, we wondered whether the binding and phagocytosis of apoptotic cells could inhibit cytokine production by stimulated macrophages. The possibility of active suppression was investigated by studying the effect of apoptotic cell uptake by macrophages stimulated to produce cytokines with LPS or zymosan. Macrophages were treated with either LPS $(1 \mathrm{ng} / \mathrm{ml})$ or zymosan $(50 \mu \mathrm{g} / \mathrm{ml})$ and at the same time exposed to apoptotic or opsonized apoptotic cells. As shown in Fig. 3, the phagocytosis of apoptotic cells by LPSstimulated macrophages was associated with decreased cytokine production except for TGF- $\beta 1$, which was enhanced significantly $(P=0.003)$ when compared with LPS-treated macrophages or those fed opsonized cells. GM-CSF was decreased significantly from macrophages treated with LPS alone or with opsonized apoptotic cells $(P=0.0001)$, IL-10 was decreased significantly compared with LPS treatment alone $(P=0.002)$, and both IL-1 $\beta$ and TNF- $\alpha$ were decreased significantly compared with macrophages treated with both LPS and opsonized apoptotic cells $(P=0.002)$. Similar results were observed with macrophages stimulated by zymosan (Fig. 4). One potential explanation for these results is that the phagocytosis of apoptotic cells resulted in macrophage loss. The macrophages were counted $18 \mathrm{~h}$ after each treatment, by lysing the cells with Zapoglobin and counting the nuclei. In five experiments, the average number of macrophages per well after stimulation with LPS was $1.4( \pm 0.2$ SEM) million and after treatment with LPS and apoptotic cells $1.3( \pm 0.2$ SEM) million.

An additional question was whether the effect of apoptotic cells was restricted to neutrophils or whether other apoptotic cells would have the same effect. Therefore, we fed the LPSstimulated macrophages UV-induced apoptotic Jurkat cells and measured the effects on TNF- $\alpha$, IL- 8 , IL-10, and TGF- $\beta$.
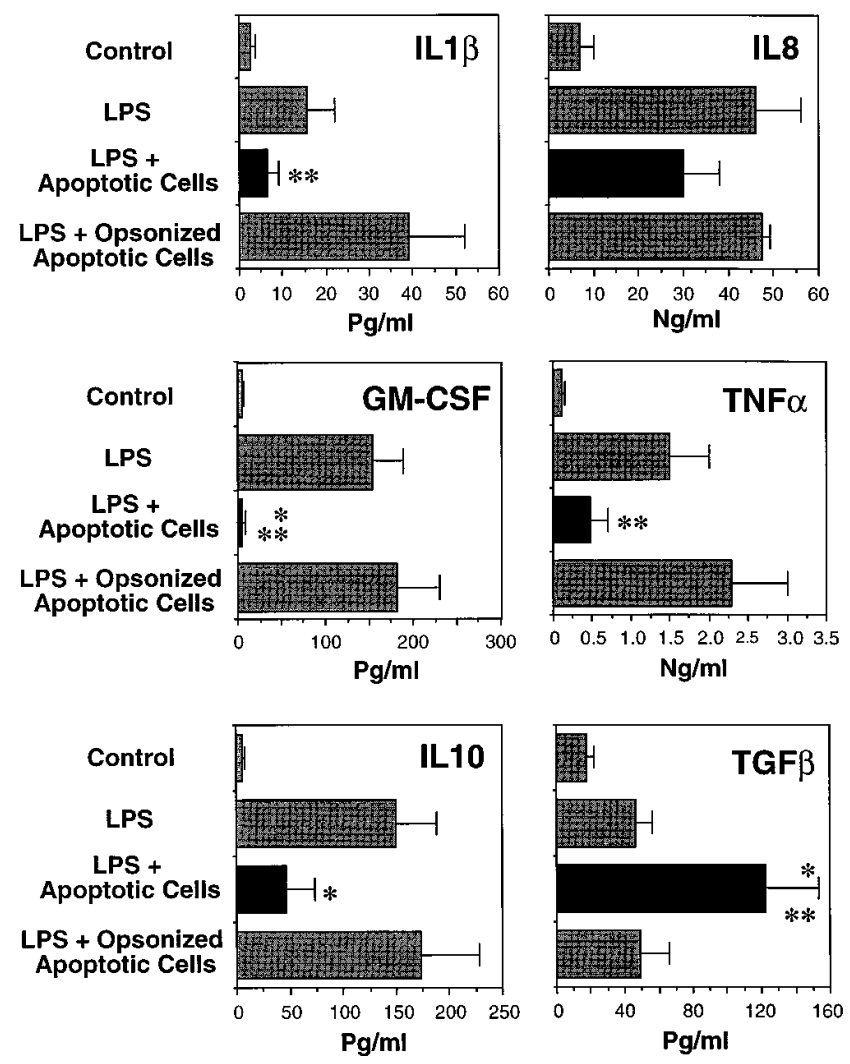

Figure 3. Phagocytosis of apoptotic cells inhibits LPS-induced proinflammatory cytokine production, but stimulates TGF- $\beta 1$. 7-d human monocyte-derived macrophages were treated with LPS at $1 \mathrm{ng} / \mathrm{ml}$; at the same time, apoptotic cells or opsonized apoptotic cells were added. Supernatants were collected $18 \mathrm{~h}$ later. The mean cytokine production \pm SEM is shown for 12 experiments; *significantly different from LPS-treated macrophages and $* *$ significantly different from LPS-treated macrophages fed opsonized apoptotic cells $(P<0.05)$. Control, Unstimulated cytokine production. 

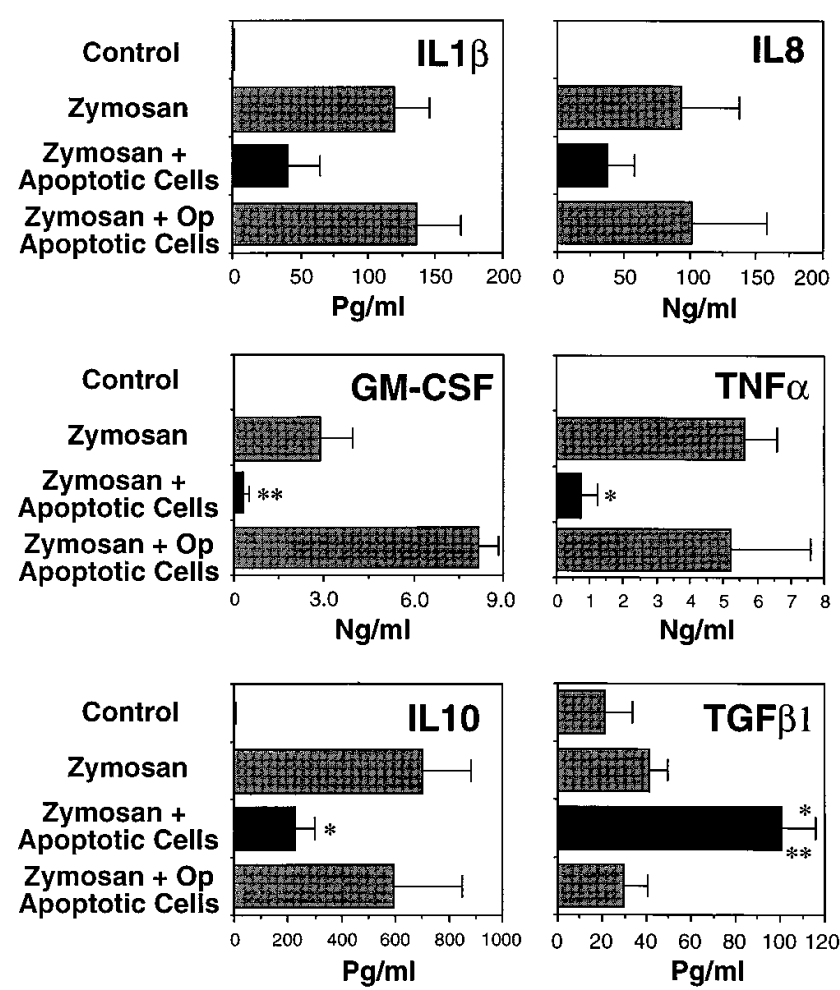

Figure 4. Phagocytosis of apoptotic cells inhibits zymosan-induced proinflammatory cytokine production but stimulates TGF- $\beta 1$. Experiments were performed as described for Fig. 2, except that zymosan at $50 \mu \mathrm{g} / \mathrm{ml}$ was used to induce cytokine secretion. The mean cytokine production \pm SEM is shown for seven experiments; *significantly different from zymosan-treated macrophages and **significantly different from zymosan-treated macrophages fed opsonized apoptotic cells $(P<0.05)$. Control, Unstimulated cytokine levels.

In five experiments, there was no statistical difference between the effects of the neutrophils compared with the Jurkat cells. Both populations had equivalent numbers of apoptotic cells and both caused decreases in TNF- $\alpha$, IL- 8 , and IL-10 and an increase in TGF- $\beta$ (data not shown).

To determine whether the inhibition occurred at the level of transcription, quantitative RT-PCR was used to determine mRNA levels for IL-8 and TNF- $\alpha$ in macrophages treated with LPS, or LPS and apoptotic neutrophils. As expected, LPS increased steady-state mRNA levels for both cytokines compared with control macrophages (Fig. 5). If, however, the macrophages were exposed to apoptotic cells at the same time they were stimulated with LPS, the mRNA levels for both cytokines were decreased 1, 4, and $18 \mathrm{~h}$ later (Fig. 5). There was no change in $\beta$-actin levels (not shown), which provided additional evidence that macrophages had not died or been lost. These data are most compatible with a decrease in transcription of cytokine message or possibly a decrease in stability of the message.

Ingestion of apoptotic cells by macrophages induces soluble inhibitors of cytokine production. Since macrophages fed apoptotic cells were able to suppress cytokine production at both the mRNA and protein levels, it was important to determine whether this was due to a soluble factor or factors. Macro- phages were fed apoptotic cells and supernatants were collected $18 \mathrm{~h}$ later. This conditioned medium was then added to macrophages at the same time as either LPS or zymosan. The inhibition of proinflammatory cytokines was even more profound than when apoptotic cells were added at the same time as the stimulus. Levels of IL-1 $\beta$, GM-CSF, TNF- $\alpha$, and IL-10 were undetectable; IL- 8 was decreased to $\leq 10 \%$ of the levels seen with LPS or zymosan alone (data not shown). TGF- $\beta 1$ was increased to levels similar to those seen from macrophages fed apoptotic cells (data not shown). These results suggested that one or more soluble inhibitors were produced by the macrophages after binding and/or phagocytosing apoptotic cells. Given that TGF- $\beta 1$ was the only cytokine which was increased after addition of apoptotic cells or conditioned media from macrophages fed apoptotic cells, it seemed a likely candidate.

Direct addition of TGF- $\beta 1$ to LPS-stimulated macrophages partially inhibited production of proinflammatory cytokines, which achieved statistical significance for IL-1 $\beta$, IL-8, GMCSF, and TNF- $\alpha$ (Fig. 6). Although the concentration used in the experiments shown was $10 \mathrm{ng} / \mathrm{ml}$, we found suppression of GM-CSF, IL-1 $\beta$, IL-10, and TNF- $\alpha$ at concentrations as low as $100 \mathrm{pg} / \mathrm{ml}$ (data not shown), which is similar to what we observed produced after the phagocytosis of apoptotic cells.
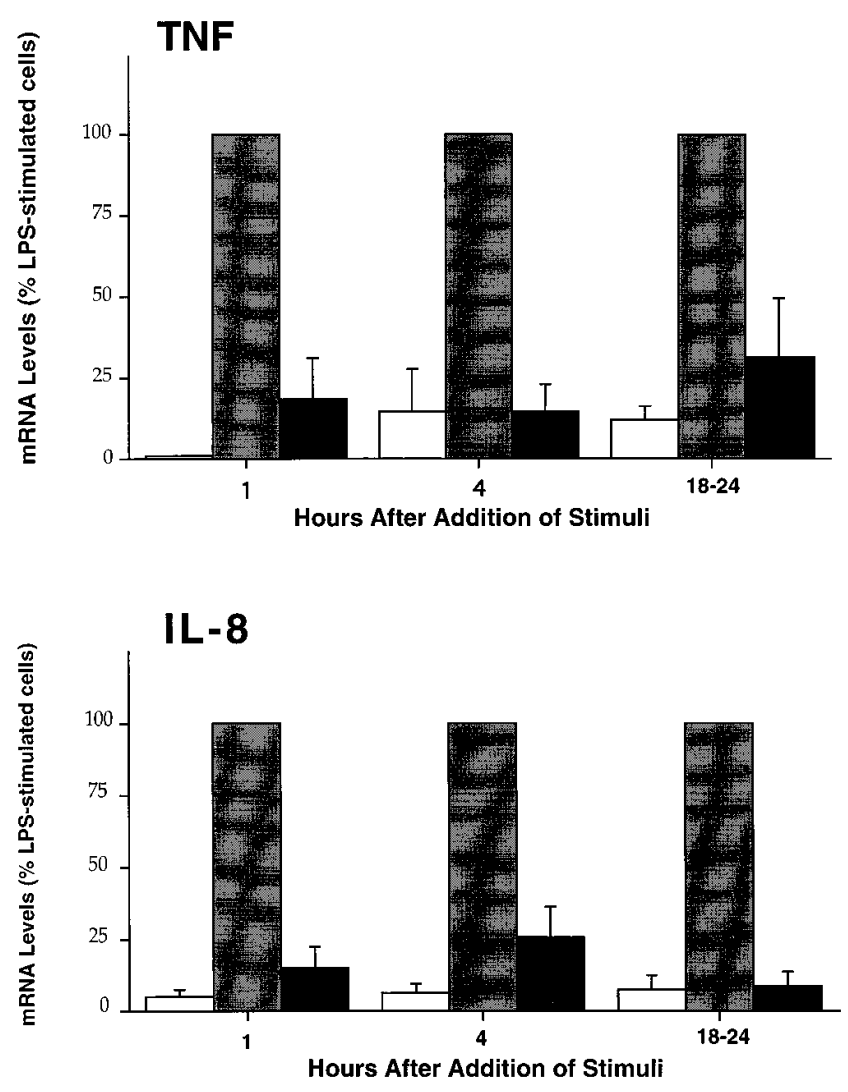

Figure 5. Phagocytosis of apoptotic cells decreases mRNA levels for IL-8 and TNF- $\alpha$ in LPS-stimulated human macrophages. The macrophages were treated exactly as described in Fig. 2, then RNA was isolated at the time points shown. Levels of mRNA for each cytokine were determined by RT-PCR as described in Methods. Data are expressed as mRNA levels $( \pm$ SEM) relative to LPS-stimulated cells which are indicated as $100 \%(n=3)$. White bars, Control; gray bars, LPS; black bars, LPS plus apoptotic cells. 

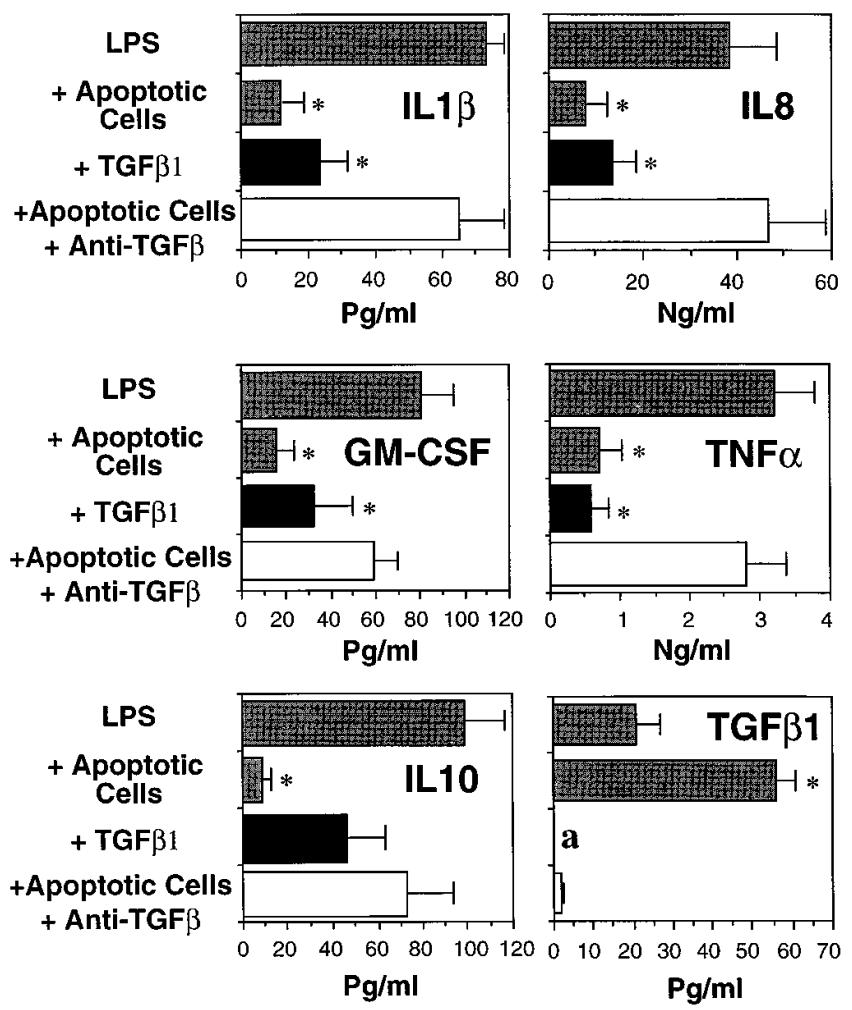

Figure 6. TGF- $\beta 1$ contributes to the inhibition of proinflammatory cytokines which occurs after phagocytosis of apoptotic cells by LPSstimulated human macrophages. Macrophages were treated with LPS at $1 \mathrm{ng} / \mathrm{ml}$ simultaneously with apoptotic cells, TGF- $\beta 1(10 \mathrm{ng} / \mathrm{ml})$, or apoptotic cells and anti-TGF- $\beta$ antibody $(100 \mu \mathrm{g} / \mathrm{ml})$, then supernatants were collected $18 \mathrm{~h}$ later. Data represent the mean and SEM for 7 experiments, except for IL-8 and TNF- $\alpha$, which represent 13 experiments; *significantly different from LPS-treated macrophages $(P<$ $0.05)$. $a$, Values for TGF- $\beta 1$ from macrophages to which it was added exogenously; levels $\geq 1 \mathrm{ng} / \mathrm{ml}$.

In addition, we found that anti-TGF- $\beta$ antibody added to LPS-stimulated macrophages fed apoptotic cells restored the inflammatory cytokine production, suggesting that endogenously produced TGF- $\beta$ played a role in inhibiting the generation of inflammatory cytokines (Fig. 6). Finally, anti-TGF- $\beta$ antibody was also found to partially block the inhibitory action of supernatants derived from macrophages which had ingested apoptotic cells (data not shown). As an additional control, PDGF (which is also secreted when mouse bone marrow macrophages ingest digestible particles, see reference 31) was added to LPS-stimulated macrophages. PDGF had little to no effect on cytokine secretion, and the addition of anti-PDGF antibody to LPS-stimulated macrophages fed apoptotic cells failed to restore cytokine production (data not shown).

Because IL-10 secretion was decreased by phagocytosis of apoptotic cells, we assumed it played no role in the inhibition of cytokine production. To confirm this, we studied the effects of adding exogenous IL-10 to LPS-stimulated macrophages, and anti-IL-10 antibody to LPS-stimulated macrophages which had phagocytosed apoptotic cells. Exogenously added IL-10 was able to inhibit production of TNF- $\alpha$ by $68 \%$ and IL- 8 by $42 \%$ when added at $10 \mathrm{ng} / \mathrm{ml}$. When IL-10 was added at $1 \mathrm{ng} /$ $\mathrm{ml}$, it inhibited TNF- $\alpha$ by $60 \%$ but had no effect on IL- 8 . However, anti-IL-10 antibody failed to restore cytokine production inhibited by the phagocytosis of apoptotic cells.

Because TGF- $\beta$ did not appear to mediate all the inhibition and IL-10 was not involved, other candidate inhibitors were examined. We have shown previously that uptake of digestible particles by mouse macrophages leads to production of PAF (32). Although PAF is generally considered a proinflammatory mediator, its role in this system was examined. Addition of PAF to macrophages along with LPS led to a decrease in all cytokines except for TGF- $\beta 1$, which was stimulated threefold $(P=0.006)$ compared with macrophages treated with LPS alone (Fig. 7). Inhibition by PAF achieved statistical significance for IL-8, IL-10, and TNF- $\alpha(P<0.05)$. In support of a role for PAF, the PAF receptor antagonist WEB 2086 led to restoration of cytokine production and a decrease in TGF- $\beta$ secretion in LPS-stimulated macrophages ingesting apoptotic cells (Fig. 7). Two other PAF receptor antagonists (CV-6209 and PCA-4248) also restored cytokine production (data not shown). Taken together, these data implicated PAF in the inhibition of cytokine production after phagocytosis of apoptotic cells.

PGE2 is an eicosanoid that, like TGF- $\beta$, has been reported to have proinflammatory or antiinflammatory properties. It
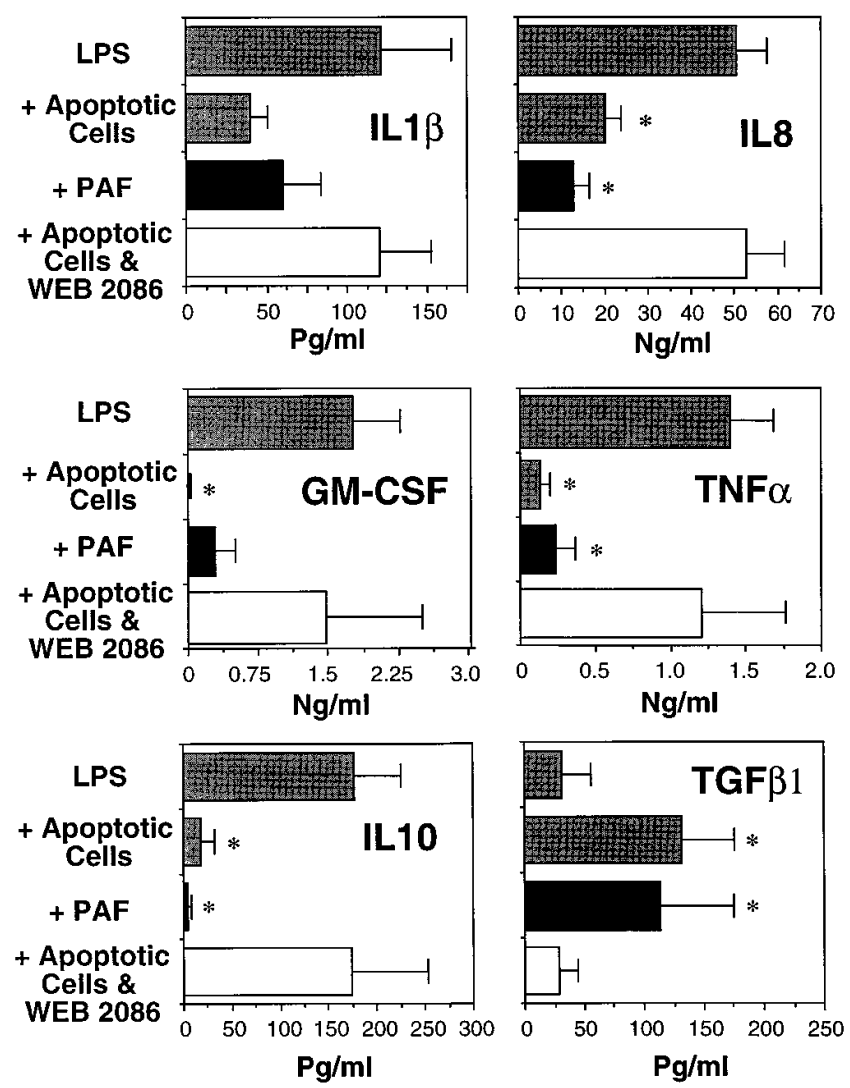

Figure 7. The addition of exogenous PAF suppresses cytokine production except for TGF- $\beta 1$. Exogenous PAF $(1 \mu \mathrm{M})$ with LPS $(1 \mathrm{ng} / \mathrm{ml})$ was added to human macrophages. PAF receptor antagonist WEB $2086(100 \mu \mathrm{M})$ was added to macrophages treated with LPS and apoptotic cells. Data represent the mean and SEM for six experiments; *significantly different from LPS-treated macrophages. 

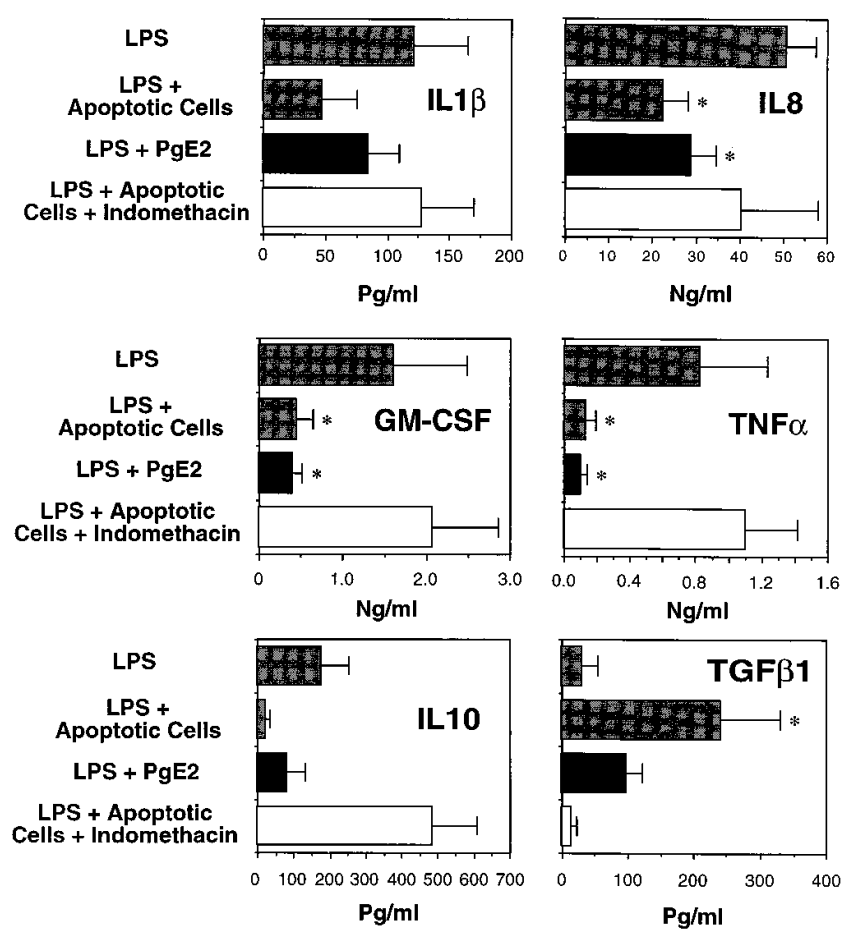

Figure 8. PGE2 suppresses cytokine production except for TGF- $\beta 1$. Exogenous PGE2 $(1 \mathrm{nM})$ with LPS $(1 \mathrm{ng} / \mathrm{ml})$ was added to human macrophages. Indomethacin $(10 \mu \mathrm{M})$ was added to macrophages treated with LPS and apoptotic cells. Data represent the mean and SEM for six experiments; *significant difference $(P<0.05)$ from LPS-treated cells.

has been shown to decrease macrophage production of cytokines such as TNF- $\alpha$ (e.g., references 40 and 41). As shown in Fig. 8, the exogenous addition of PGE2 to LPS-stimulated macrophages decreased their production of all the cytokines except TGF- $\beta 1$, which was stimulated (Fig. 8). By adding indomethacin to LPS-stimulated macrophages that had ingested apoptotic cells, proinflammatory cytokine production was restored and TGF- $\beta 1$ production was inhibited slightly.
Phagocytosis of apoptotic cells increased PGE2 production while decreasing TXB2 and LTC4. Since PGE2 affected cytokine production in this system, the ability of these macrophages to produce PGE2 and other eicosanoids was examined. Supernatants were collected from unstimulated human macrophages 1,4 , and $18 \mathrm{~h}$ after addition of apoptotic cells or opsonized apoptotic cells, and analyzed for PGE2, PGD2, LTC4, and TxB2. PGD2 levels were undetectable or very low in all cases $(\leq 170 \mathrm{pg} / \mathrm{ml})$. Opsonized apoptotic cells induced a 5-fold increase in PGE2 levels, but unopsonized apoptotic cells induced as much as a 15-fold increase detectable $1 \mathrm{~h}$ after the cells were added (Fig. 8). Compared with those from control macrophages, TxB2 levels were decreased at all time points by the addition of apoptotic cells, and LTC4 levels were decreased at 4 and $18 \mathrm{~h}$; opsonized cells were stimulatory for both eicosanoids (Fig. 9).

\section{Discussion}

Phagocytosis of apoptotic cells was shown to inhibit macrophage production of GM-CSF, IL-1 $1 \beta$, IL-8, IL-10, TNF- $\alpha$, TxB2, and LTC4, but to increase production of TGF- $\beta 1$, PGE2, and PAF. At this point, we have not determined whether these effects result from binding to macrophage receptors for apoptotic cells or from the actual uptake process itself. These effects were apparent in unstimulated macrophages as well as those stimulated with LPS or zymosan. Furthermore, TGF- $\beta 1$, $\mathrm{PAF}$, and PgE2 appeared to mediate the decrease in inflammatory cytokine production, because addition of each of these to LPS-stimulated cells decreased cytokine production, and because addition of anti-TGF- $\beta$ antibody, PAF receptor antagonists, or indomethacin to LPS-treated macrophages which had ingested apoptotic cells restored cytokine production.

We propose that the lack of proinflammatory mediator production results not from a passive lack of stimulation, but from an active suppressive mechanism involving the autocrine/ paracrine action of TGF- $\beta$, PGE2, and PAF. The precise nature of the interaction between these three mediators is under further study. The data presented here suggest the possibility that PAF and/or PGE2 can stimulate the production of TGF$\beta 1$. Therefore, TGF- $\beta$ may be the most important antiinflam-
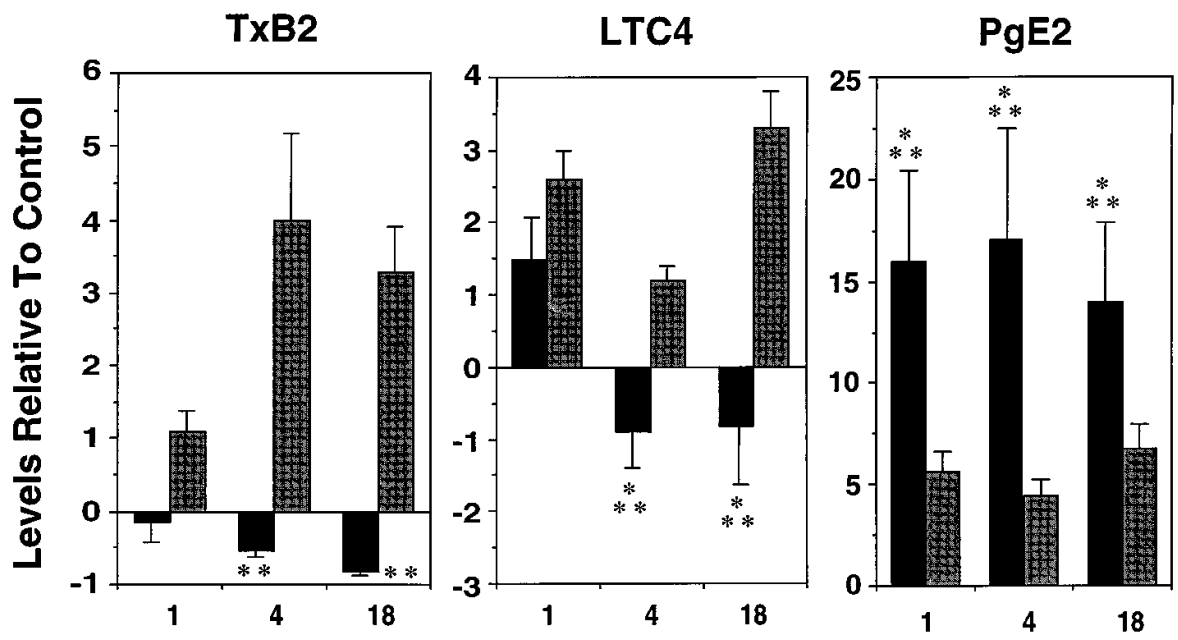

Figure 9. Phagocytosis of apoptotic cells inhibits secretion of TxB2 and LTC4, but stimulates secretion of PGE2 by human macrophages. Unstimulated macrophages were cultured with apoptotic cells (black bars) or opsonized apoptotic cells (gray bars) and supernatants were collected at the time points shown. Eicosanoid levels were measured by competitive EIA as described in Methods. Data are shown as levels relative to untreated macrophages which (in $\mathrm{pg} / \mathrm{ml}$ ) were for TxB2, 811 \pm 374 (1 h), 757 \pm 225 (4 h), and 2838 $\pm 786(18 \mathrm{~h})$; LTC4, 146 \pm 40 ( $1 \mathrm{~h}), 259 \pm 98(4 \mathrm{~h})$, and $183 \pm 69$ (18 h); PgE2, 90 23 (1 h), $78 \pm 28$ $(4 \mathrm{~h})$, and $104 \pm 30(18 \mathrm{~h})(n=10)$. *Significantly different from control levels; **significantly different from macrophages fed opsonized apoptotic cells $(P<0.05)$. 
matory mediator ultimately generated or PAF and PGE2 can have both direct and indirect effects on proinflammatory cytokine production. We have done preliminary experiments to assess these possibilities by adding anti-TGF- $\beta$ antibody to LPS-stimulated macrophages that had been treated with either PAF or PGE2 to look for effects on TNF- $\alpha$ and IL-8 production; however, results were not consistent. The regulation appears to be quite complex and needs to be studied further before conclusions are drawn.

Initially, IL-10 seemed a likely candidate for potential antiinflammatory activity in this system, based on observations that it is a potent suppressor of inflammatory cytokines including IL-1, IL-6, IL-8, and TNF- $\alpha$, and it can also suppress production of superoxide anions and nitrous oxide (42-46). However, production of IL-10 was inhibited by the phagocytosis of apoptotic cells, and anti-IL-10 antibody failed to restore the production of cytokines inhibited by apoptotic cells. This does not rule out a role for IL-10 in vivo, but suggests that macrophages would be an unlikely source.

The mechanisms by which TGF- $\beta$, PAF, and PgE2 are produced by macrophages after phagocytosis of apoptotic cells and how they downregulate inflammatory cytokine and eicosanoid production are under active investigation. The decreased mRNA levels for IL- 8 and TNF- $\alpha$ observed after ingestion of apoptotic cells are compatible with decreased transcription of cytokine messages; however, we cannot rule out alterations in message stability. The regulation is likely to be complex, given that we have at least three candidates that appear to affect proinflammatory cytokine production. TGF- $\beta$ itself has been shown to inhibit cytokine production on a number of levels. It is known to increase transcription of its own message, but its effects on other cytokines are more complicated. TGF- $\beta$ has been reported to have no effect on TNF- $\alpha$ mRNA levels, release of preformed TNF- $\alpha$, or its degradation; rather it inhibited translation of TNF- $\alpha$ mRNA (47). TGF- $\beta$ has also been shown to inhibit the release of IL-1, to downregulate the number of IL-1 receptors, and to increase production of IL-1ra $(33,34)$. Therefore, it may act as an antiinflammatory agent on a variety of levels. The importance of TGF- $\beta$ in the regulation of inflammation is illustrated by the observations that knockout mice have severe and generalized inflammatory disorders $(48,49)$.

In this system, we studied macrophages which primarily used the VnR and CD36 mechanism for recognition of apoptotic cells. It is still not known whether the other receptors mediating uptake of apoptotic cells would have the same suppressive effect; however, preliminary data suggest that uptake mediated by the PS recognition mechanism also inhibits proinflammatory cytokine production. As we found for mouse bone marrow macrophages, treating human macrophages with particulate $\beta$-glucan for $48 \mathrm{~h}$ led to recognition of apoptotic cells through a PS-inhibitable mechanism (Warner, M.L., V.A. Fadok, D.L. Bratton, and P.M. Henson, manuscript submitted for publication). After phagocytosis of apoptotic cells, glucantreated macrophages also produced increased levels of TGF$\beta 1$ and decreased levels of GM-CSF, IL-1 $\beta$, IL-8, IL-10, and TNF- $\alpha$. These results support the hypothesis that removal of apoptotic cells by "apoptotic" receptors rather than opsonic receptors such as FcR or CR3 leads to suppression of inflammatory cytokine production.

The selective effect of apoptotic cell uptake on macrophage eicosanoid generation suggests either that these macrophages use different PGH synthase enzymes for TxA2 and PGE2 production and/or undergo a switch in metabolism of PGH2 by PGE2 synthase versus thromboxane synthase. In support of the latter possibility, we have observed that $\mathrm{TNF}-\alpha$ induced PGE2 synthase activity in mouse bone marrow-derived macrophages fed zymosan compared with macrophages which had not been pretreated with TNF- $\alpha$ (Fournier, T., V.A. Fadok, and P.M. Henson, manuscript submitted for publication). The somewhat delayed effect of apoptotic cell uptake on LTC4 may indicate that an effect on lipoxygenase pathways (5 lipoxygenase or LTC4 synthase) takes longer for implementation. It is also possible (though less likely) that differential effects are mediated by alterations in local substrate (arachidonate and/or PGH2) distribution.

It seems likely that the nature and duration of the inflammatory response is determined by competition between proinflammatory and antiinflammatory uptake mechanisms. Our observations suggest that phagocytosis of apoptotic cells not only prevents the release of toxic and immunogenic intracellular contents, but also stimulates the macrophages to express an antiinflammatory or suppressive phenotype. Both mechanisms are likely to be critical in the resolution of inflammation. If this is true, then disorders in either uptake or response to apoptotic cells by macrophages could contribute to chronic inflammation.

\section{Acknowledgments}

We would like to acknowledge John Savill and Christopher Gregory for helpful discussions and the suggestion of additional experimental controls and Devitt et al. for permission to allude to their work.

This work was supported by National Institutes of Health grants GM-48211 and HL-34303, and by the Cancer Center at University of Colorado's Health Sciences Center.

\section{References}

1. Wyllie, A.H., J.F.R. Kerr, and A.R. Currie. 1980. Cell death: the significance of apoptosis. Int. Rev. Cytol. 68:251-307.

2. Savill, J., V. Fadok, P. Henson, and C. Haslett. 1993. Phagocyte recognition of cells undergoing apoptosis. Immunol. Today. 14:131-136.

3. Grigg, J.M., J.S. Savill, C. Sarraf, C. Haslett, and M. Silverman. 1991. Neutrophil apoptosis and clearance from neonatal lungs. Lancet. 338:720-722.

4. Cox, G., J. Crossley, and Z. Xing. 1995. Macrophage engulfment of apoptotic neutrophils contributes to the resolution of acute pulmonary inflammation in vivo. Am. J. Respir. Cell. Mol. Biol. 12:232-237.

5. Haslett, C., J.S. Savill, M.K.B. Whyte, M. Stern, I. Dransfield, and L.C. Meagher. 1994. Granulocyte apoptosis and the control of inflammation. Phil. Trans. R. Soc. Lond. B. 345:327-333.

6. Duvall, E., A.H. Wyllie, and R.G. Morris. 1985. Macrophage recognition of cells undergoing programmed cell death (apoptosis). Immunology. 56:351-358.

7. Savill, J., I. Dransfield, N. Hogg, and C. Haslett. 1990. Vitronectin receptor-mediated phagocytosis of cells undergoing apoptosis. Nature. 343:170-173.

8. Savill, J.S., N. Hogg, Y. Ren, and C. Haslett. 1992. Thrombospondin cooperates with CD36 and the vitronectin receptor in macrophage recognition of neutrophils undergoing apoptosis. J. Clin. Invest. 90:1513-1522.

9. Fadok, V.A., D.R. Voelker, P.A. Campbell, J.J. Cohen, D.L. Bratton, and P.M. Henson. 1992. Exposure of phosphatidylserine on the surface of apoptotic lymphocytes triggers specific recognition and removal by macrophages. $J$. Immunol. 148:2207-2216.

10. Fadok, V.A., J.S. Savill, C. Haslett, D.L. Bratton, D.E. Doherty, P.A Campbell, and P.M. Henson. 1992. Different populations of macrophages use either the vitronectin receptor or the phosphatidylserine receptor to recognize and remove apoptotic cells. J. Immunol. 149:4029-4035.

11. Fadok, V.A., D.J. Laszlo, P.W. Noble, L. Weinstein, D.W.H. Riches, and P.M. Henson. 1993. Particle digestibility is required for induction of the phosphatidylserine recognition mechanism used by murine macrophages to phagocytose apoptotic cells. J. Immunol. 151:4274-4285.

12. Pradhan, D., S. Krahling, P. Williamson, and R.A. Schlegel. 1997. Multiple systems for recognition of apoptotic lymphocytes by macrophages. Mol. Biol. Cell. 8:767-778. 
13. Sambrano, G., and D. Steinberg. 1995. Recognition of oxidatively damaged and apoptotic cells by an oxidized low density lipoprotein receptor on mouse peritoneal macrophages: role of membrane phosphatidylserine. Proc. Natl. Acad. Sci. USA. 92:1396-1400.

14. Platt, N., H. Suzuki, Y. Kurihara, T. Kodama, and S. Gordon. 1996. Role for the class A macrophage scavenger receptor in the phagocytosis of apoptotic thymocytes in vitro. Proc. Natl. Acad. Sci. USA. 93:12456-12460.

15. Fukasawa, M., H. Adachi, K. Hirota, M. Tsujimoto, H. Arai, and K. Inoue. 1996. SRB1, a class B scavenger receptor, recognizes both negatively charged liposomes and apoptotic cells. Exp. Cell. Res. 222:246-250.

16. Flora, P.K., and C.D. Gregory. 1994. Recognition of apoptotic cells by human macrophages: inhibition by a monocyte/macrophage specific monoclonal antibody. Eur. J. Immunol. 24:2625-2632.

17. Luciani, M.-F., and G. Chimini. 1996. The ATP binding cassette transporter $\mathrm{ABC} 1$, is required for the engulfment of corpses generated by apoptotic cell death. EMBO (Eur. Mol. Biol. Organ.) J. 15:226-235.

18. Schlegel, R.A., M. Stevens, K. Lumley-Sapanski, and P. Williamson. 1993. Altered lipid packing identifies apoptotic thymocytes. Immunol. Lett. 36: 283-288.

19. Mower, D.A., D.W. Peckham, V.A. Illera, J.K. Fishbaugh, L.L. Stunz, and R.F. Ashman. 1994. Decreased membrane phospholipid packing and decreased cell size precede DNA cleavage in mature mouse B cell apoptosis. $J$. Immunol. 152:4832-4842.

20. Koopman, G., C.P.M. Reutelingsperger, G.A.M. Kuijten, R.M.J. Keehnen, S.T. Pals, and M.H.J. van Oers. 1994. Annexin V for flow cytometric detection of phosphatidylserine expression on B cells undergoing apoptosis. Blood. $84: 1415-1420$

21. Homburg, C.H.E., M. de Haas, A.E.G.Kr. von dem Borne, A.J. Verhoeven, C.P.M. Reutelingsperger, and D. Roos. 1995. Human neutrophils lose their surface Fc $\gamma$ RIII and acquire annexin $\mathrm{V}$ binding sites during apoptosis in vitro. Blood. 85:532-540.

22. Martin, S.J., C.P.M. Reutelingsperger, A.J. McGahon, J.A. Rader, R.C.A.A. van Schie, D.M. LaFace, and D.R. Green. 1995. Early redistribution of plasma membrane phosphatidylserine is a general feature of apoptosis regardless of the initiating stimulus: inhibition by overexpression of bcl-2 and abl. J. Exp. Med. 182:1545-1556.

23. Verhoven, B., R.A. Schlegel, and P. Williamson. 1995. Mechanisms of phosphatidylserine exposure, a phagocyte recognition signal, on apoptotic $\mathrm{T}$ lymphocytes. J. Exp. Med. 182:1597-1601.

24. Morris, R.G., A.D. Hargreaves, E. Duvall, and A.H. Wyllie. 1984. Hormone-induced cell death. II. Surface changes in thymocytes undergoing apoptosis. Am. J. Pathol. 115:426-436.

25. Dini, L., F. Autuori, A. Lentini, S. Oliverio, and M. Piacentini. 1992. The clearance of apoptotic cells in the liver is mediated by the asialoglycoprotein receptor. FEBS Lett. 296:174-178.

26. Gregory, C.D., P.K. Flora, H.S. Bhogal, and W. De Smet. 1995. Phagocytic clearance of apoptotic cells: novel pathways identified by monoclonal antibodies to cell surface components. J. Cell. Biochem. Suppl. 19B:312. (Abstr.)

27. Dransfield, I. A.-M. Buckle, J.S. Savill, A. McDowall, C. Haslett, and N. Hogg. 1994. Neutrophil apoptosis is associated with a reduction in CD16 (FcyRIII) expression. J. Immunol. 153:1254-1263.

28. Rotello, R.J., P.-A. Fernandez, and J. Yuan. 1994. Anti-apogens and anti-engulfens: monoclonal antibodies reveal specific antigens on apoptotic and engulfment cells during chicken embryonic development. Development. 120: $1421-1431$

29. Meagher, L.C., J.S. Savill, A. Baker, R.W. Fuller, and C. Haslett. 1992. Phagocytosis of apoptotic neutrophils does not induce macrophage release of thromboxane B2. J. Leukocyte Biol. 52:269-273.

30. Stern, M., J. Savill, and C. Haslett. 1996. Human monocyte-derived macrophage phagocytosis of senescent eosinophils undergoing apoptosis. Mediation by $\alpha \mathrm{v} \beta 3 / \mathrm{CD} 36 /$ thrombospondin recognition mechanism and lack of phlogistic response. Am. J. Pathol. 149:911-921.

31. Noble, P.W., P.M. Henson, C. Lucas, C.M. Mora-Worms, P.C. Carre, and D.W.H. Riches. 1993. Transforming growth factor- $\beta$ primes macrophages to express inflammatory gene products in response to particulate by an autocrine/paracrine mechanism. J. Immunol. 151:979-989.

32. Rose, D.M., V.A. Fadok, D.W.H. Riches, K.L. Clay, and P.M. Henson. 1995. Autocrine/paracrine involvement of platelet-activating factor and transforming growth factor- $\beta$ in the induction of phosphatidylserine recognition by murine macrophages. J. Immunol. 155:5819-5825.

33. Ruscetti, F., L. Varesio, A. Ochoa, and J. Ortaldo. 1993. Pleiotropic effects of transforming growth factor- $\beta$ on cells of the immune system. Ann. NY Acad. Sci. 685:488-500.

34. Wahl, S.M. 1994. Transforming growth factor $\beta$ : the good, the bad, and the ugly. J. Exp. Med. 180:1587-1590.

35. Haslett, C., L.A. Guthrie, M.M. Kopaniak, R.B. Johnston, and P.M. Henson. 1985. Modulation of multiple neutrophil functions by preparative methods or trace concentrations of bacterial lipopolysaccharide. Am. J. Pathol. 119:101-110.

36. Savill, J.S., P.M. Henson, and C. Haslett. 1989. Macrophage phagocytosis of aging neutrophils in inflammation. Programmed cell death in the neutrophil leads to its recognition by macrophages. J. Clin. Invest. 83:865-875.

37. Pradelles, P., J. Grassi, and J. Maclouf. 1990. Enzyme immunoassays of eicosanoids using acetylcholinesterase. Methods Enzymol. 187:24-34.

38. Westcott, J.Y., K. Johnston, R.A. Batt, S.E. Wenzel, and N.F. Voelkel. 1990. Measurement of peptidoleukotrienes in biological fluids. J. Appl. Physiol. 68:2640-2648

39. Kelly, R.W., S. Deam, M.J. Cameron, and R.F. Seamark. 1986. Measurement by radioimmunoassay of prostaglandins as their methyl oximes. Prostaglandins Leukotrienes Med. 24:1-14.

40. Kunkel, S.L., M. Spengler, M.A. May, R. Spengler, J. Larrick, and D. Remick. 1988. Prostaglandin E2 regulates macrophage-derived tumor necrosis factor gene expression. J. Biol. Chem. 263:5380-5384.

41. Strassman, G., V. Patil-Koota, F. Finkelman, M. Fong, and T. Kambayashi. 1994. Evidence for involvement of interleukin 10 in the differential deactivation of murine peritoneal macrophages by prostaglandin E2. J. Exp. Med. 180:2365-2370.

42. de Waal Malefyt, R., J. Abrams, B. Bennett, C.G. Figdor, and J.E. de Vries. 1991. Interleukin 10 (IL-10) inhibits cytokine synthesis by human monocytes: an autoregulatory role of IL-10 produced by monocytes. J. Exp. Med. 174:1209-1230.

43. Fiorentino, D.F., A. Zlotnik, T.R. Mosmann, M. Howard, and A O'Garra. 1991. IL-10 inhibits cytokine production by activated macrophages. $J$. Immunol. 147:3815-3822.

44. Oswald, I.P., T.A. Wynn, A. Sher, and S.L. James. 1992. Interleukin 10 inhibits macrophages microbicidal activity by blocking the endogenous production of tumor necrosis factor $\alpha$ required as a costimulatory factor for interferon $\gamma$-induced activation. Proc. Natl. Acad. Sci. USA. 89:8676-8680.

45. Niiro, H., T. Otsuka, M. Abe, H. Satoh, T. Ogog, T. Nakano, Y. Furukawa, and Y. Niho. 1992. Epstein-Barr virus BCRF1 gene product (viral in terleukin 10) inhibits superoxide anion production by human monocytes. Lymphokine Cytokine Res. 11:209-214.

46. Niiro, H., T. Otsuka, S. Kuga, Y. Nemoto, M. Abe, N. Hara, T. Nakano, T. Ogo, and Y. Niho. 1994. IL-10 inhibits prostaglandin E2 production by lipopolysaccharide-stimulated monocytes. Int. Immunol. 6:661-664.

47. Bogdan, C., J. Paik, Y. Vodovotz, and C. Nathan. 1992. Contrasting mechanisms for suppression of macrophage cytokine release by transforming growth factor- $\beta$ and interleukin-10. J. Biol. Chem. 267:23301-23308.

48. Shull, M.M., I. Ormsby, A.B. Kier, S. Pawlowski, R.J. Diebold, M. Yin, R. Allen, C. Sidman, G. Proetzel, D. Calvin, N. Annunziata, and T. Doetschman. 1992. Targeted disruption of the mouse transforming growth factor- $\beta 1$ gene results in multifocal inflammatory disease. Nature. 359:693-699.

49. Kulkarni, A.B., C.-G. Huh, D. Becker, A. Geiser, M. Lyght, K.C. Flanders, A.B. Roberts, M.B. Sporn, J.M. Ward, and S. Karlsson. 1993. Transforming growth factor $\beta 1$ null mutation in mice causes excessive inflammatory response and early death. Proc. Natl. Acad. Sci. USA. 90:770-774. 